\title{
Educators' Competence Level in Effective Communication and Proficient Use of Information Communication Technologies (ECPUICT)
}

\author{
Nisar Abid, Tariq Hussain, Almas Shoaib \\ University of the Punjab, Pakistan
}

\begin{abstract}
This study aim was to assess Elementary School Teachers' (ESTs) competence level in Effective Communication and Proficient Use of Information Communication Technologies (ECPUICT). It is significantly important for educational authorities to know the competence level of ESTs regarding communication skills and skills to use information communication technologies. Cross-sectional survey method of descriptive research was used to collect data. Population was consisted of all the ESTs (398 female and 355 male $=753$ ) working in public sector elementary schools of district, Lahore. 80 female and 71 male ESTs were selected by using proportionate cluster stratified random sampling technique of probability sampling. Researchers developed observational rating scale which was comprised of three sub-scales (i.e. Knowledge \& understanding, dispositions, and performance \& skills). Percentage, mean score, standard deviation and t-test was applied. Results indicate that most of the ESTs have moderate competence level in ECPUICT. Furthermore, there was insignificance difference female and male teachers' competence level in two subscales (knowledge and understanding, and performance \& skills) while statistically significant difference was exist in female and male ESTs' dispositions. Overall, results showed that there was insignificant difference between female and male ESTs competence level in ECPUICT. It is recommended that Government should take steps to improve teacher communication skills as well as skills to use Information Communication Technologies by preservice and in-service training programs.
\end{abstract}

\section{Introduction}

Quality of education based on components of curriculum, teachers' pedagogical knowledge, content knowledge, professional qualification, communication skills, and use of technologies in teaching-learning process [7] [18]. Moreover, Singh believed that quality of education seems impossible without having content knowledge, professional knowledge, teaching skills, communication skills and abilities to use of technologies [16]. Bhargava and Agra thought that learners' performance and quality of education depend upon teachers' competence [1] [3]. They said that good teacher is committed to his/her work, have skills to communicate, have abilities to use different technologies in teaching-learning process. Content knowledge, pedagogical knowledge, professional qualification, communication abilities, and skills to use technologies make a teacher competent [4] [17].

Competence depend upon knowledge, attitude and skills needed to perform better during teaching-learning process while competence in teaching are pedagogical knowledge, practical skills and abilities to use different technologies that teachers need to transfer knowledge. Therefore, teachers are known by his/her subject matter knowledge, teaching abilities, skills to use technologies, and own competence in conveying ideas to learners [7] [10] [12] [14].

Teachers are known as change agent which play a key role in improving the quality of education. However, their role is considered to communicate and transfer knowledge to learners. During the previous two decades technologies have emerged in all discipline of life especially in the field of education. Developing countries try to use technologies in teaching-learning process. Likewise, in Pakistan Government took initiative to introduce different technologies in school education system. Ministry of Education, Government of Pakistan developed National Professional Standards for teachers in 2009. One of the teaching standards is Effective Communication and Proficient Use of Information Communication Technologies (ECPUICT). Hence, this study was designed to assess the educators' competence level in ECPUICT.

\section{Objectives of the study}

- To assess educators' competence level in Effective Communication and Proficient Use of Information Communication Technologies (ECPUICT).

- To find out the difference between educators' competence level regarding ECPUICT on the basis of gender. 


\subsection{Research Questions}

- What is the educators' competence level in Effective Communication and Proficient Use of Information Communication Technologies (ECPUICT)?

- Is there any significant difference between educators' competence level regarding ECPUICT on the basis of gender?

\section{Literature Review}

Profession of teaching is considered as building block for every profession. Education contours the future of the learners which makes them a good citizen. However, educators play a vital role in safeguarding the effectiveness, quality in education which established educated society [1]. Moreover, prosperity of society depends upon in what way efficiently its people attentions are educated to take the numerous duties in society. Profession of teaching demand that greater emphasis should be given on ongoing education of teachers. While, world had proposed a plan for growth of proficient abilities in teachers in numerous ways. Educator assessment and their licensing system has been improved throughout the world [3].

In 21 st century, teachers need to promote the learner's curiosity in content by presenting how knowledge relates with real world situation [4]. Educators' role seems to enhance learner's interest, which supports them to become enduring students. With the fiscal help of USAID, the UNESCO and Policy and Planning Wing of Ministry of Education Pakistan is instigating and establishing teacher education programs in Pakistan. In all provinces of Pakistan, teachers have been developed in collaboration with stakeholder. Nonetheless, the professional standards are design for primary level educators and may be adapted for elementary level teachers.

The standards about knowledge and understanding, dispositions and skills are developed to: describe skills, capabilities and features deliberated to be crucial for educators, guide the comprehensive growth of in-service and pre-service programs of teacher education; develop rules, processes and arrangements for recognizing these programs, organizations proposing them, assure society regarding the worth of their teachers and educational outcomes [19]. The suggested standards for assessment of educators' capabilities are as follows:

1. Subject Matter Knowledge.

2. Human Growth and Development
3. Knowledge of Islamic/ Ethical Values/Social Life Skills

4. Instructional Planning and Strategies

5. Assessment

6. Learning Environment

7. Effective communication and proficient use of information communication technologies

8. Collaboration and Partnerships

9. Continuous Professional Development and Code of Conduct

10. Teaching of English as a second/foreign language (ESL/EFL).

Standard based growth of teachers is part of a universal program of value assertion in numerous arenas of human exertion. Excellence in learning examines with a precarious standpoint the aspects that subsidize to educational excellence, monitors their attendance in organization, and assesses the influence teachers have on learners' education.

Likewise, competency is a vigorous pattern of teachers' performance. It remnants an appraisal except essentially illustrated the capabilities of educators at elementary school level. The educators' competency means their abilities and skills to execute their occupations adequately. Educator competence be different from "educator effectiveness" and "educator performance". Educator competence contaminate is an unchanging characteristic of the educator that doesn't modify applicably when educator pass from one position to a different one. "Educator competency states the cognitive knowledge which effected learners' performance. On the other hand, performance falls among these notions indicating the capability to perform regarding to a model of educator" [15].

The theoretic context is based on literature review and current studies on communication [2] [5] [6] [8] [9] [11] [13]. Communication during teaching learning is more complex and impulsive than in many other conditions. Teaching-learning procedure will not take place without communication. Hence, educators with good communication abilities will make more positive teaching-learning atmosphere for learners [9]. However, somebody having good communication skills has the prospective to affect others communication tactics which lead to accomplishment of goals. Teachers have a countless transaction to do with communication. They transformer knowledge and information in a numerous way (e.g. gestures, speaking, body language, and written word etc.).

Literature illustrated that numerous studies have stated that the vital problems of teacher education in Pakistan. Various reasons have been cited in the literature. Shakir and Abeeb observed the performance of the teachers in classroom [15]. They found little variation in three levels slightly aware were $26.00 \%$, moderately aware were $29.20 \%$ while somewhat aware were $33.20 \%$, teachers. 
Haider, Qasim and Ameen observed Elementary School Teachers' (ESTs) competence level of female and male ESTs working in public sector schools. The results showed that majority of the teachers were somewhat aware about competence explained in National Professional Standards for Teachers [7]. Zhu, Wang, Cai and Engels observed teacher's competence level and concluded that they were moderately competent [20].

Shakira and Hussian evaluate the school teachers' competencies with respect to national professional standard in Pakistan, based on five levels defined in rubrics. They select secondary school teachers from public sector secondary schools. Observational survey was method used to assess the performance of the educators in the field. Percentage, chi- Square and simple mean identified was applied to analyze the data. Results indicates that majority of the educators were found at developing level, However, $30.1 \%$ were proficient and $27.1 \%$ were at emerging level whereas $14.5 \%$ were found as proficient teachers and $7.5 \%$ were found at lowest level.

Shakira, Hussian and Zafar measure the effective communication and proficient use of information communication technology. Subjects were contained of secondary school educators of Punjab Province. Observational survey method was used to assess the educators in field. Data were analyzed by using statistical formulas of percentage, mean and chi-square. The analysis of various levels determines that more than half of the teachers did not recognize the significance of communication skills in education. Furthermore, Use of ICTs in teaching-learning process was also endure question marks for educators, more than half of the educators somewhat recognize the effective use of information and communication technologies.

\section{Research methodology}

Quantitative approach was adopted whereas descriptive research design was used; cross-sectional survey method was adopted by using observational rating scale to assess the competence level of educators regarding Effective Communication and Proficient Use of Information Communication Technologies (ECPUICT). Population was contained of all the elementary school educators working in public sector elementary schools of district Lahore. Targeted population was already consisted of two strata's (male and female). According to School Education Department (2017 there are 218 (90 male and 128 female) elementary schools in district Lahore while working elementary school teachers was 753 (355 male and 398 female).

Two stage sampling method was used to select the sample. Firstly, 20\% schools were selected from each stratum (27 female and 18 male) by using cluster proportional stratified random sampling technique.
Latterly, average of four educators were selected from each selected school through simple random sampling technique without replacement method. Therefore, sample was comprised of 151 elementary school teachers (71 male and 80 female). Observational rating scale was developed by the researchers which was constructed on the basis of formerly classified levels of teacher accreditation by Policy and Planning Wing, Ministry of Education, Pakistan. Observational rating scale contained of 19 items which were alienated into its predefined subscales (i.e. Knowledge and Understanding, dispositions and performance and skills) in National Professional Standards for Teachers in Pakistan. Each item was of rating scale was constructed on five-point Likert-type scale ranging from 'unaware' to 'extremely aware'.

Table 1: Description of level of rating scale

\begin{tabular}{lll}
\hline Level & \multicolumn{2}{c}{ Description } \\
\hline 0 & Not Demonstrated & Unaware \\
1 & Emerging & Slightly aware \\
2 & Developing & Somewhat aware \\
3 & Proficient & Moderately aware \\
4 & Accomplished & Extremely Aware \\
\hline
\end{tabular}

Table 2: Description of scale

\begin{tabular}{ll}
\hline Level & Description \\
\hline 0 & $\begin{array}{l}\text { Educator does not have this competency at } \\
\text { this time. }\end{array}$ \\
1 & $\begin{array}{l}\text { Educator have some difficulty of } \\
\text { demonstrating this competency. }\end{array}$ \\
2 & $\begin{array}{l}\text { Educator have done satisfactory job for } \\
\text { demonstrating this competency. }\end{array}$ \\
3 & $\begin{array}{l}\text { Educator have done good job of } \\
\text { demonstrating this competency. } \\
\text { Educators have done an excellent job of } \\
\text { demonstrating this competency. }\end{array}$ \\
\hline
\end{tabular}

Validity of rating scale was made sure from faculty members and $\mathrm{PhD}$ scholars of education. Pilot study was made on 30 educators to make sure the value of reliability, it was 0.910 at Cronbach's Alpha level which is acceptable. The researchers personally visited the selected 45 elementary schools. We observed teacher's competence level by using participant observation during September to November. Each observation was contained of 45 minutes. Percentage, Mean and Standard deviation was calculated by using descriptive statistics whereas t-test was applied to determine the difference between female and male educators' competence level by using inferential statistical technique through 
Statistical Package for Social Sciences (SPSS) version 21.

\section{Data Analysis and Interpretation}

The results related to knowledge and understanding of educators in Effective Communication and Proficient Use of Information Communication Technologies (ECPUICT) indicates that educators were more competent in clear verbal communication during teaching-learning process while they were moderately competent in others five competence. The results about dispositions in ECPUICT showed that teachers were more active listener whereas in others competence they were moderately competent. Results regarding performance and skills in ECPUICT indicated that teachers were more competent in to speak clearly in their native language however moderately competent in others competence. Results of t-test describes that there was significant difference between female and male educators' competence level in dispositions of ECPUICT. Nonetheless, there was insignificant difference between female and male educators' competence level in other two subscales of ECPUICT.

Table 3: Knowledge and understanding

\begin{tabular}{cccccccc}
\hline & Level & Level & Level & Level & Level & $M$ & $S D$ \\
& 0 & 1 & 2 & 3 & 4 & & \\
\hline S1 & 0.0 & 11.9 & 31.1 & 42.4 & 14.6 & 2.60 & 0.881 \\
S2 & 7.3 & 15.2 & 41.8 & 28.5 & 7.2 & 2.13 & 1.004 \\
S3 & 5.3 & 11.2 & 31.8 & 37.8 & 13.9 & 2.44 & 1.037 \\
S4 & 7.3 & 16.5 & 31.8 & 35.8 & 8.6 & 2.22 & 1.058 \\
S5 & 21.9 & 14.6 & 25.8 & 32.5 & 5.3 & 1.85 & 1.242 \\
S6 & 2.0 & 11.9 & 32.5 & 33.8 & 19.9 & 2.58 & 1.003
\end{tabular}

Table 3 reveals that teachers' competence level regarding sub-scale knowledge and understanding of effective communication and proficient use of information communication technologies at the time of observation. It shows that $42.4 \%$ teachers were practice clear verbal communication during teaching however no one found at lowest level. In response of second statement most of the teachers were found at level-2 which means they done a satisfactory job to exhibit nonverbal communication during teaching. Meanwhile, $7.2 \%$ teachers were at desired level nonetheless $7.3 \%$ were unaware to demonstrate non-verbal communication.

Majority of the teachers were at level-3 (proficient teachers) which means they were moderately aware to demonstrate written communication during lecture. Conversely, $5.3 \%$ does not have this competency at that time. The results of the response 4 were indicated that majority of them could proficiently operate educational technologies during class on the other hand $7.3 \%$ were at level-0. Furthermore, $32.5 \%$ teachers were moderately aware that how to use diverse A.V Aids in classroom while a reasonable number of teachers were found at level-0 (not demonstrated). The analysis of various levels describes that most of the educators were found at level-3 (moderately awareness) whereas 33.8\% teachers had done a good job to exhibit rise and fall in voice during teaching. The mean score of statement of teachers practice clear verbal communication during teaching was greater than rest of the competence $(\mathrm{M}=2.60, \quad \mathrm{SD}=0.881>\mathrm{M}=2.13, \quad \mathrm{SD}=1.004 ; \quad \mathrm{M}=2.44$, $\mathrm{SD}=1.037 ; \mathrm{M}=2.22, \mathrm{SD}=1.058 ; \mathrm{M}=1.85, \mathrm{SD}=1.242 ;$ $\mathrm{M}=2.58, \mathrm{SD}=1.003)$.

\section{Table 4: Dispositions}

\begin{tabular}{cccccccc}
\hline & Level & Level & Level Level & Level $M$ & $S D$ \\
& 0 & 1 & 2 & 3 & 4 & & \\
\hline S1 & 0.7 & 19.2 & 33.1 & 37.1 & 9.9 & 2.36 & 0.927 \\
S2 & 0.0 & 12.6 & 30.4 & 41.0 & 15.9 & 2.60 & 0.902 \\
S3 & 0.7 & 14.6 & 33.8 & 31.7 & 19.2 & 2.54 & 0.985 \\
S4 & 4.6 & 18.6 & 36.4 & 28.5 & 11.9 & 2.25 & 1.039 \\
S5 & 8.6 & 17.3 & 34.4 & 33.1 & 6.6 & 2.12 & 1.052 \\
S6 & 2.0 & 13.9 & 29.8 & 36.4 & 17.9 & 2.54 & 1.005 \\
& & & & & & & \\
\hline
\end{tabular}

Table 4 explains the teacher competence level about sub-scale dispositions of effective communication and proficient use of information communication technologies at various level. It demonstrates that most of the educators were found at level-3 (moderately aware) while $9.9 \%$ educators done an excellent job to appreciate the cultural values in classroom. The results of response 2 illustrated that majority of the teachers done a good job for demonstrating active listener however, no one found unaware and a limited number of teachers were found at the desired level of this competency.

Teacher responds appropriately to all students concluded that a significant number of teachers were found at the desired level of this competency on the other hand a limited number of teachers were unaware at the time of observation.

Teacher encourages variety of opinion among learners defined that most of the educators were found at level-2 (developing) in rubric. However, $4.6 \%$ teachers do not encourage diversity of opinion among students. 
In response 5 teacher enhances student's learning by using educational technologies, majority of teacher were found at level-2 (developing teacher) and level-3 (proficient teacher) hence few of them were observed at the desired level of competence.

On the other hand, the results about teachers exhibited eye contact while teaching concluded that majority of teachers were proficient at exhibiting eye contact while teaching and were found at level-2 and level-3 whereas significant number of teachers were found at the desired level. The mean score of teachers is active listener was greater than all other competency of dispositions $(\mathrm{M}=2.60, \mathrm{SD}=0.902 ; \mathrm{M}=2.36, \mathrm{SD}=0.927$; $\mathrm{M}=2.54, \quad \mathrm{SD}=0.985 ; \quad \mathrm{M}=2.25, \quad \mathrm{SD}=1.039 ; \quad \mathrm{M}=2.12$, $\mathrm{SD}=1.052 ; \mathrm{M}=2.54, \mathrm{SD}=1.005$.

\section{Table 5: Performance and skills}

\begin{tabular}{cccccccc}
\hline & Level & Level & Level & Level & Level & $M$ & $S D$ \\
& 0 & 1 & 2 & 3 & 4 & & \\
\hline S1 & 0.0 & 14.6 & 27.8 & 40.4 & 17.2 & 2.60 & 0.939 \\
S2 & 3.3 & 15.9 & 37.7 & 34.4 & 8.6 & 2.29 & 0.949 \\
S3 & 3.3 & 16.6 & 35.7 & 37.8 & 6.6 & 2.28 & 0.932 \\
S4 & 6.6 & 18.6 & 38.5 & 29.8 & 6.6 & 2.11 & 1.004 \\
S5 & 6.0 & 15.9 & 39.7 & 29.8 & 8.6 & 2.19 & 1.005 \\
S6 & 3.3 & 14.5 & 30.5 & 28.5 & 23.2 & 2.54 & 1.100 \\
S7 & 7.9 & 14.6 & 33.1 & 31.2 & 13.3 & 2.27 & 1.113 \\
\hline
\end{tabular}

Table 5 explain the teachers' competence level regarding sub-scale performance and skills of effective communication and proficient use of information communication technologies at the time of observation. It illustrates that in competency to speak clearly in native language majority of the educators were found at level-3 (Proficient teacher) while a fewer number of teachers were found at desired level of competence. In competency regarding teacher engages himself in activities to model effective communication strategies. Most of the participant were found at level-2 (somewhat aware) and level-3 (moderately aware) whereas a fewer number of teachers was found at the desired level of competency in rubric educator involves himself in actions to model effective communication tactics.

The results of response 3 showed that majority of the educators were found at level-3 (proficient teacher) while a negligible number of teachers were found competent they were at level-4 in this rubric. Educator engages himself/herself in actions to model questioning techniques in encouraging critical thinking describes that majority of the educators were found at level-2 (developing teacher) and a fewer number of teachers were at the desired level of this competency. Whereas teacher speaks in a way that exhibits warmth to culture concludes that most of the educators were found at developing teacher in this rubric. An insignificant number of teachers were found at the desired level of competency.

Response 6, teacher engages himself to give homework/assignment emerged that a significant number of teachers were found at the desired level while most of the educators done a acceptable job to demonstrate this competency. The results of educator make objectives of teaching-learning clear to learners showed that a fewer number of teachers were found at the desired level of competence in this rubric. However, $33.1 \%$ teachers were found at level-2 (somewhat aware). Mean score of teacher speaks clearly in native language was greater than all other competency of performance and skills $(\mathrm{M}=2.60, \mathrm{SD}=0.939>\mathrm{M}=2.29, \mathrm{SD}=0.949$; $\mathrm{M}=2.28, \quad \mathrm{SD}=0.932 ; \quad \mathrm{M}=2.11, \quad \mathrm{SD}=1.004 ; \quad \mathrm{M}=2.19$, $\mathrm{SD}=1.005 ; \mathrm{M}=2.54, \mathrm{SD}=1.100 ; \mathrm{M}=2.27, \mathrm{SD}=1.113$.

Table 6: Independent samples t-test on gender

\begin{tabular}{|c|c|c|c|c|c|c|}
\hline & \multicolumn{2}{|c|}{ Male (71) } & \multicolumn{2}{|c|}{ Female (80) } & \multirow[t]{2}{*}{$t$} & \multirow[t]{2}{*}{$p$} \\
\hline & $M$ & $S D$ & $M$ & $S D$ & & \\
\hline $\mathrm{K} \& U$ & 13.70 & 3.743 & 13.90 & 4.274 & 0.289 & 0.269 \\
\hline $\mathrm{D}$ & 15.15 & 3.916 & 13.76 & 4.270 & 2.081 & 0.041 \\
\hline P\&S & 17.04 & 4.603 & 15.61 & 5.220 & 1.764 & 0.080 \\
\hline Total & 45.90 & 10.359 & 43.28 & 12.848 & 1.369 & 0.169 \\
\hline
\end{tabular}

Note: $d f=149$.

Table 6 indicates that the results of independent sample t- test on the basis of gender in three subscale (Knowledge and understanding, Dispositions, Performance and Skills) and overall competence in Effective Communication and Proficient Use of Information Communication Technologies (ECPUICT). It exhibited that there was insignificant difference in educators' competence in two sub-scales (i.e. knowledge $\&$ understanding and performance \& skills) and overall competence in ECPUICT on the basis of gender as $\mathrm{t}(149)=0.289, p=0.269 ; \mathrm{t}(149)=1.764, p=0.080$ and $\mathrm{t}(149)=1.369, p=0.169$ correspondingly. However, data also showed that there was significant difference in educators' dispositions regarding ECPUICT as $\mathrm{t}(149)=$ 2.081, $p=0.041$.

\section{Discussion}

The 21st century has perceived remarkable explosion of information and solicitation of 
information communication technologies, hastening the right to use to information, improving obsolesces of the current information and skills [15]. Decent communication supports to form a bridge between learners and educators, allowing educators to make the content understandable to their learners [16]. School educator usually recognize the significance of communication skills in education. Efficient use of Information Communication Technologies (ICTs) support effective teaching-learning atmosphere. It has been measured that majority of the educators slightly recognize the use of ICTs. Inquire method heartens the appropriate participation of learners in educational process [4].

The present study aimed to assess educators' competence level regarding Effective Communication and Proficient Use of Information Communication Technologies (ECPUICT). The findings indicated that most of educators have moderate competent level in ECPUICT. These results support the finding of Haider, Qasim and Ameen. However, Shakir and Hussain found that most teachers during evaluation were found weak in effective communication and efficient use of information and communication [7]. They said that elementary school teachers of district Lodhran have moderate competence level [7]. Nonetheless, Shakira et al. concluded that educators were not using information communication technologies appropriately and rated as poor class of educator about information and its application. Moreover, there was insignificant difference between female and male educators' competence level in ECPUICT. However, previous researches gave contrary results. They concluded that a significant difference exists in female and male educators' competence level in ECPUICT [7] [15].

\section{Conclusions}

The excellence of teaching-learning process based on curriculum and educators' competence level. Recently, the competence of educators is observed in around the world, however, some efforts are made in Pakistan. This study aim was to assess the educators' competence level in Effective Communication and Proficient Use of Information Communication Technologies (ECPUICT). Researchers concluded that educators have moderate competence level in ECPUICT. In addition, there was insignificant difference in male and female educators' competence level in two sub-factors (i.e. knowledge and understanding and performance and skills) whereas a significant difference existed in female and male educators' dispositions in ECPUICT.

ECPUICT are the most significant feature to use information and instructional technologies for curriculum enhancement, assessment and learning products. Results also concluded that more than educators rarely recognize the significance of communication skills during instruction. Educators slightly recognize the effective use of information communication technologies while few educators were found at desire level of competency. Furthermore, most of the educators could not operate and measure learners' test items and assignments by using information communication technologies.

\section{Implications of the Study}

- Government should take steps to improve teacher communication skills as well as the skills to use different technologies during teaching-learning process by pre-service and in-service training of educators.

- This study was conducted on elementary school educators of district Lahore, so it is recommended for future researchers to be on the educators of other districts of Punjab to identify the educators' competence level, which may be helpful for better decision making to the enlargement of education in Pakistan.

- This study demonstrations that majority of the educators almost never try to implement governmental policies in classroom therefore it is suggested majority of the educators during observation were found week in using ICTs.

- Most of head teachers stated that the educator training organizations were not equipped with latest technologies and taught educators through traditional approaches. Hence, it is suggested that the educator training organizations should be equipped with latest technologies.

- It is also suggested that ministry of education of Pakistan should arrange workshops and design programs to enhance teachers' performance regarding ICTs.

- This study was based on observational rating scale similarly forthcoming researchers should study the others scales to measure teachers' competence level and use students' achievement to examine the influence of educators' competence level on learner performance.

\section{References}

[1] Agra, P., (2005) Teachers in 21st Century. New Delhi, India: Prentice Hall.

[2] Alberto, V., (2013). Motivation and learning strategies in the use of ICTs among university students. Computers \& Education, 6(1), 52-58. 
[3] Bhargava, M., \& Bharagava, P., (2005). Appraisal of Modern Education. New Delhi, India: Prentice Hall.

[4] Cruickshank, D. R., Jenkins, D. B., \& Metcalf, K. K. (2005). The act of teaching. New York, USA: McGrawHill Companies.

[5] Domenech, F., \& Gomez, A., (2014). The relationship among students' and teachers' thinking styles, psychological needs and motivation. Learning and Individual Differences, 29(1), 89-97.

[6] Duta, N., Panisoara, G., \&Panisoara, I. O., (2015). The Effective Communication in Teaching. Diagnostic study regarding the academic learning motivation to students. Procedia-Social and Behavioral Sciences, 186, 1007-1012.

[7] Haider, Z. S., Qasim, M., \& Ameen, S., (2015). Applying Standardized Rubrics for Assessing the Instructional Competence of Elementary School Teachers (EST) in Pakistan. Advances in Social Sciences Research Journal,2(3), 39-50. Doi: 10.14738 / assrj.23.832.

[8] Jurik, V., (2014). Predicting students' cognitive learning activity and intrinsic learning motivation: How powerful are teacher statements, student profiles, and gender? Learning and Individual Differences, 32, 132139.

[9] Kenneth, D. M., (2007). Classroom Teaching Skill. Edisi ke-6. Mc Graw Hill.

[10] Kumari, S., Sriwastwa, S. D., (2005). Education. Skills and competencies. New Delhi, India: Isha Books.

[11] Lambrechts, W., (2013). The integration of competences for sustainable development in Higher Education: an analysis of bachelor programs in management. Journal of Cleaner Production, 48, 65-73.

[12] Levpuscek, M. P., Peklaj, C., (2007). Motivation of student teachers in educational psychology course: its relation to the quality of seminar work and final achievement. San Francisco, California: Jossey-Bass Inc Pub.

[13] Panisoara, G., \& Panisoara, I.O., (2012). Motivation in a crisis society. Romanian perspective. Procedia Social and Behavioral Sciences, 33, 20-24.

[14] Rychen, D. S., Salganik, L. H., (Eds.). (2003). Key competencies for a successful life and well-functioning society. Hogrefe Publishing. Gottingen, Germany: Hogrefe\& Huber.

[15] Shakir, M., \& Adeeb, A.M., (2014). Performance Appraisal: An Evaluation of Teachers' Competencies Based on National Professional Standards in Pakistan. International Review of Social Science2(12), 532-539.

[16] Singh, M. S., (2007). Teacher Education in Dilemma. New Delhi, India: Adhyayan Publishers \& Distributors.

[17] Sujathamalini, J., (2007). Learning difficulties in children: Teacher competencies. New Delhi, India: Discovery Publishing House.

[18] Tomlinson, S., (2005). Education in a post welfare society. UK: McGraw-Hill Education.

[19] UNESCO, (2008). Good Practices and International Trends of Teacher Accreditation and Certification with Analysis and Recommendations for Pakistan under the Strengthening Teacher Education in Pakistan (STEP) Programme. Retrived December 19, 2016 fromhttp://www.unesco.org.pk/education/teachereducati on/reports/rp21.pdf

[20] Zhu, C., Wang, D., Cai, Y. H., \& Engels, N., (2013). What core competencies are related to teachers' innovative teaching? Asia-Pacific Journal of Teacher Education, 41(1), 9-27. 